\title{
Baroreflex Sensitivity and Essential Hypertension in Adolescents
}

\author{
N. HONZÍKOVÁ, B. FIŠER
}

Department of Physiology, Faculty of Medicine, Masaryk University, Brno, Czech Republic

Received October 9, 2008

Accepted October 29, 2008

On-line November 4, 2008

\section{Summary}

It has been known for many years that baroreflex sensitivity is lowered in hypertensive patients. There are several known factors implicating this association, e.g. high blood pressure leads to remodeling of the carotid arterial wall, to its stiffness and to a diminished activation of baroreceptors; leptin released from a fatty tissue activates the sympathetic nervous system etc. On the other hand, low baroreflex sensitivity (BRS, usually quantified in $\mathrm{ms} / \mathrm{mmHg}$ ) can be inborn. Studies on primary hypertension in children and adolescents have brought new information about the role of baroreflex in the development of an early stage of primary hypertension. BRS lower than $3.9 \mathrm{~ms} / \mathrm{mmHg}$ was found in $5 \%$ of healthy subjects. This value approaches the critical value for the risk of sudden cardiac death in patients after myocardial infarction and corresponds to the value present in hypertensive patients. A decreased BRS and BRSf (baroreflex sensitivity expressed in $\mathrm{mHz} / \mathrm{mmHg}$, index independent of the mean cardiac interval), was found not only in children with hypertension, but also in those with white-coat hypertension. This is in accordance with a single interpretation. The decrease of BRS/BRSf precedes a pathological blood pressure increase. The contribution of obesity and BRS/BRSf to the development of hypertension in adolescents was also compared. Both factors reach a sensitivity and a specificity between $60 \%$ and $65 \%$, but there is no correlation between the values of the body mass index and BRS either in the group of hypertensive patients or in healthy controls. If a receiver operating curve (sensitivity versus specificity) is plotted for both values together using logistic regression analysis, a sensitivity higher than $70 \%$ and a specificity over $80 \%$ are reached. This means that low baroreflex sensitivity is an independent risk factor for the development of primary hypertension. Studies demonstrate that adolescents with increased blood pressure and with BRS under $7 \mathrm{~ms} / \mathrm{mmHg}$ should be given care and intensively motivated to change their lifestyle including a change in diet and increase in physical activity.

\section{Key words}

Essential hypertension - Baroreflex sensitivity - Adolescents • Obesity • Genetics

\section{Corresponding author}

Prof. Dr. Nataša Honzíková, CSc., Department of Physiology, Faculty of Medicine, Masaryk University, Komenského nám. 2, CZ-662 43 Brno, Czech Republic. Fax: +420-549 493 748. E-mail: nhonziko@med.muni.cz

\section{Introduction}

Primary hypertension in adults is one of the most important problems of health care in the world. High blood pressure is estimated to be responsible yearly for approximately 6 million disability-adjusted life years (DALYs) lost in the EU. A higher harmful effect is produced by tobacco with 7 and a half million DALYs lost, whereas alcohol, overweight and cholesterol are responsible for 4 million DALYs lost, and other risk factors as low physical activity, low fruit and vegetable intake, drugs and occupational risks are responsible for a loss in a range between half and one and a half million DALYs per year (Health and Consumer Protection Directorate 2006).

There is a linear relationship between blood pressure and the relative risk of ischemic heart disease and stroke, but these are not the diseases of adolescence. This corresponds to the fact that the prevalence of hypertension linearly increases with age. It is under $5 \%$ for men between 18 and 29 years of age, $40 \%$ at the age 
between 50 and 59 years, and $60 \%$ at the age over 80 years. The regression line of increasing prevalence of hypertension starts in women 10 years later, but it has a steeper slope, so that prevalence of hypertension in women older than 80 years is $70 \%$ (Kaplan 2001).

Primary hypertension is not known in newborns. Chronic hypertension can be seen in renal artery stenosis of thrombosis, congenital renal structural abnormalities, coarctation of the aorta, and bronchopulmonary dysplasia. Wilms' tumour joins these diagnoses in infancy up to 6 years. At the age between 6 and 10 years, primary hypertension could be rarely seen besides renal structural, inflammatory and parenchymal diseases, and renal artery stenosis. In adolescents, primary hypertension and renal parenchymal diseases occur. It is evident that renal hypertension is the main problem in childhood (Kaplan 2001).

When high blood pressure is measured in a child without any of the diagnoses listed above, blood pressure values taken at a repeated measurement are lower than the first measured value, and the sensitivity of a high pressure value which was measured in a child, is only 0.17 for a diagnosis of hypertension 10 years later (Kaplan 2001). This finding is not surprising. A drop of values during repeated measurements corresponds to the statistical phenomenon of a regression to the mean and further to the fact that high values of blood pressure could be influenced by a stress response which is stimulated by many examinations during childhood. Psychological stress increases sympathetic activity and leads to a decrease of baroreflex sensitivity. The increased sympathetic activity has a harmful effect especially in older population, but it is not clear whether this is also the case in children and adolescents. It is reported that the prevalence of essential hypertension in adolescents increases and that it could be linked with increased obesity (Freedman et al. 1999, Sorof et al. 2002). We had studied especially the role of baroreflex in the development of essential hypertension in children and adolescents for several years (Nováková et al. 2000).

\section{Ambulatory blood pressure monitoring}

In 1948 Franz Halberg (University of Minnesota) suggested the use of a 24-h blood pressure monitoring as the basic diagnostic method of hypertension. This method became a standard routine 40 years later. So far, comparing the accuracy of a diagnosis of hypertension considered by measurements in outpatient clinics with that determined by a $24-\mathrm{h}$ blood pressure monitoring, it is at about $40 \%$. It has been used in daily practice to diagnose hypertension by repeated measurements of blood pressure in outpatient clinics, but this is unsatisfactory for scientific purposes. Therefore, we use 24-h blood pressure monitoring in all our genetic studies, studies of impairment of baroreflex, and in studies of negative side effects of drug therapy.

\section{Baroreflex sensitivity}

Baroreflex is the most important nervous regulatory mechanism of blood pressure homeostasis. However, this unquestionable fact does not give the possibility of deciding whether baroreflex plays a role in the development of essential hypertension. It has been known for many years that baroreflex sensitivity is lowered in hypertensive patients (Gribbin et al. 1971). This is not surprising. High blood pressure leads to remodeling of the carotid arterial wall, its stiffness increases, and the stiff carotid sinus is less distensible during a blood pressure increase. Baroreceptors as mechanoreceptors stimulated by distension of the carotid wall are therefore less activated. We have proved a correlation between the thickness of the carotid intimamedia, hypertension, and low baroreflex sensitivity in adults (Honzíková et al. 2006a). Nevertheless, the answer to the question whether primary low baroreflex sensitivity could also be the cause of the development of hypertension remained unsolved. It was supposed that baroreflex was unsubstantial for the development of essential hypertension for a long time. There are three fundamental objections to baroreflex involvement in the long-term control of mean blood pressure based on the following experiments (Cowley 1992).

Immediately after baroreceptor denervation in experimental animals, blood pressure is increased by more than $50 \mathrm{mmHg}$, but during several days blood pressure returns to the original level because of a loss of blood volume by an increased urinary output. The result is an increase of blood pressure variability with the mean value of blood pressure corresponding to the value before the denervation.

In hypertonic patients the curve of the relationship between a blood pressure value and activation of baroreceptors is shifted to higher values of blood pressure relating to baroreceptor activation, known as resetting. The baroreflex gain was found insufficient to account for long-term stability of mean blood pressure. 
Based on the interpretation of these experiments it was concluded that the main function of baroreflex is the short-time regulation of blood pressure. However, the recent experiment with chronic electrical stimulation of the carotid baroreceptor afferent nerve fibers and chronic recording of renal sympathetic activity as well as some other experiments demonstrated the role of baroreceptors in the-long term control of blood pressure (Brooks and Sved 2005, Thrasher 2005). The experiments with longterm monitoring of experimental animals demonstrated that baroreflex plays a more important role in the cardiovascular physiology than was formerly supposed. In addition, the latest study of the therapy of chronic hypertension resistant to antihypertensive drugs by a stimulation of carotid nerves showed that baroreflex is likewise effective in long-term blood pressure regulation (Filippone and Bisognano 2007). It seems that it is time for a re-evaluation of the physiological function of baroreflex. In our opinion, it is necessary to include into consideration also the anatomical and evolutionary aspects.

The locations of baroreceptors in arteries supplying the brain suggest their possible role in cerebral circulation. The perfusion of various areas of brain during cerebral activity is fine-tuned, and one of the important mechanisms keeping the brain perfusion constant is represented by autoregulation. A rapid decrease of blood pressure by $20-30 \mathrm{mmHg}$ elicits a decrease of vascular brain resistance which can be demonstrated by ultrasonic measurement of blood flow velocity in the middle cerebral artery and blood flow in the common carotid artery in humans (Savin et al. 1997). This autoregulation is shifted to higher pressures in hypertensive subjects; the decreased brain perfusion with clinical consequence caused by a rapid, therapeutically induced decrease of blood pressure is the result (Strandgaard and Haunso 1987). It can be concluded that the protection of brain vessels is an important function of baroreflex activity. Lower blood pressure also decreases the load on the heart and its metabolic demand. This role is not so important because increased load of the heart by increased blood pressure in a giraffe does not have negative consequences for the life of this animal. The perfusion of brain is more important.

However, this speculation does not answer the question why baroreflex is important if blood pressure can be decreased by renal pressure natriuresis.

The answer is provided by the reaction of blood pressure on movement. In baroreceptor-intact animals the movements elicit an increase of blood pressure, which improves the perfusion of the working muscles. This response is missing in baroreceptor-denervated animals (Nishida et al. 2002). A short-term attenuation of the baroreflex gain for the time of exercise brings an advantage in the evolution because of better perfusion and thus a better oxygen supply of muscles during the fear and rage reactions. The increase of blood pressure is too short to elicit remodeling of the arterial wall of cerebral arteries. The protection of brain arteries is abolished for a short time only.

On the other hand, the baroreflex resetting as seen in hypertensive subjects and experimental animals is of no advantage in the evolution. Because of the resetting, baroreflex ceases to play a protective role in the hypertensive subject and a possible damage of brain vessels is inevitable. Despite these negative consequences, the baroreflex resetting is a unique mechanism, which makes the function of the baroreflex possible.

There are no etalons for measurement calibration in the human and animal body. This is valid e.g. for both blood pressure and blood glucose concentration. If the response of insulin secretion to the increase of blood glucose is too high, a down-regulation of the insulin receptors takes place so that the concentration of glucose remains on a constant level for the most part of the day. For baroreflex, the mean blood pressure determines the value of the set point of the baroreflex for several hours. This fact complicates the explanation of the role of baroreflex in hypertension. However, the role of the resetting of baroreceptors in hypertension should not be overestimated because the majority of hypertensive patients are "dippers", with almost normal values of blood pressure during the night.

The above-described facts suggest that baroreflex plays a role in the development of hypertension, although explicit proofs are missing. We supposed that a study of baroreflex sensitivity in children might give answer to such a question.

\section{Study of baroreflex sensitivity in children}

The first method for the heart rate baroreflex sensitivity determination was based on intravenous administration of phenylephrine and measurement of blood pressure increase followed by prolongation of cardiac intervals (BRS, quantified in $\mathrm{ms} / \mathrm{mmHg}$ ). At the age between 16 and 50 years, a baroreflex sensitivity is 
decreasing in both normotensive people and hypertensive patients (Gribbin et al. 1971). Naturally, for the ethical reason such a method was inapplicable in pathophysiological studies in children.

We had a method, which enabled us to approach the baroreflex sensitivity evaluation in children for many years. In the early nineties of the previous century we had developed a non-invasive method of heart rate baroreflex sensitivity determination by spectral analysis of the continuous non-invasive blood pressure recording in finger arteries (Honzíková et al. 1992). Using this method, we showed a BRS decrease in patients after myocardial infarction aged between 50 and 70 years. On the other hand, it seemed that BRS in children did not change with age (Semrád et al. 1998). As we found large interindividual differences in resting values of BRS in children and young adults and since BRS has been known to react sensitively to different types of load including mental stress (Honzíková et al. 1996), we performed a study of reproducibility of BRS in which we confirmed its individually characteristic features (Jíra et al. 2006).

Our non-invasive method enabled us to study BRS in larger groups of children. We examined 415 children, adolescents, and young adults between 11 and 20 years. In this group, we did not find any significant age-dependent change of BRS if determined as usually in $\mathrm{ms} / \mathrm{mmHg}$. However, we did find a significant agedependent BRS decrease in this group similar to adults, when baroreflex sensitivity was expressed by the BRSf index in $\mathrm{mHz} / \mathrm{mmHg}$ (Závodná et al. 2006). This is because the cardiac interval gets prolonged in this age period and BRS correlates positively with the cardiac interval. BRSf is an index independent of cardiac interval. After normalization of BRS on the cardiac interval by multiregression analysis, its decrease with age is also proved in childhood and adolescence (Závodná et al. 2006). It seems that an age-dependent decrease of BRS is caused by an age-dependent increase of arterial stiffness, which was documented by an increase of the pulse wave velocity in many studies. A further interesting finding is the fact that we found BRS lower than $3.5 \mathrm{~ms} / \mathrm{mmHg}$ in $5 \%$ of healthy subjects in this group of children, adolescents, and young adults. Such low BRS approximates the critical value of BRS for sudden cardiac death in patients after myocardial infarction (Honzíková et al. 2000), and it corresponds to the value that we found in hypertonic patients (Honzíková et al. 2006a). This indicates that the later development of hypertension is to some extent predetermined by low BRS in childhood as one of the risk factors for essential hypertension in adulthood. We tried to get some support for such hypothesis in our further studies.

\section{Baroreflex sensitivity in children with white coat hypertension}

We compared 54 subjects aged between 11 and 21 years, who had repeatedly high casual blood pressure (higher than 95th percentile limit of blood pressure for the corresponding age at three consecutive measurements taken at least one week apart) with an age-matched control group of 108 subjects (Honzíková et al. 2006b). Based on 24-h blood pressure monitoring the tested group with higher blood pressure was divided into two groups with either hypertension or white-coat hypertension. We found decreased BRS in both these groups tested. We supposed a lower BRS in hypertonic subjects, but the finding of a significantly lower BRS in those with whitecoat hypertension answers the question what is first hypertension or low BRS. Children, adolescents, and young adults with white-coat hypertension have physiological blood pressure over 24 hours and there is no reason for remodeling the vessel's wall. Nevertheless, they have lower BRS (and BRSf as well) than healthy controls. These results suppose the only interpretation low BRS precedes blood pressure increase.

\section{Genetic disposition}

Nowadays there is no doubt that the disposition to the development of essential hypertension is genetically conditioned. It is beyond the extent of this paper to give a review of all the factors studied. But what are the data about genetic differences in the gain of baroreflex?

Older human studies provided estimates of the genetic effect on BRS indirectly. Normotensive and borderline hypertensive subjects with a family history of hypertension exhibited a decrease in BRS compared with normotensives without a family history of hypertension (Iwase et al. 1984). Tank et al. (2001) assessed the genetic influence on BRS in 149 monozygotic and dizygotic twin pairs. BRS did not differ significantly between these two groups, but the variance and covariance analysis showed a significant correlation for BRS in monozygotic twins only. This correlation was only slightly attenuated after correction for the body mass index and blood pressure. Thus, BRS heritability was 
shown. It was suggested by Kardos et al. (2001) that a significant part of interindividual differences in baroreflex sensitivity may reflect genetic heterogeneity. Genetic studies were a logical step in the verification of this hypothesis.

The genetic contribution to the sensitivity of baroreflex control of heart rate could be supposed in different properties of the components of the baroreceptor reflex arc, including baroreceptors, baroreceptor afferent nerves, central neuronal transmission serving the baroreflex, efferent autonomic pathways and sinoatrial node. Numerous ligands, receptors, and channels have to be taken into account. Many factors acting in the peripheral system also exist independently in the brain, such as the renin-angiotensin system, nitric oxide, and endothelin-1. Therefore it might be expected, with respect to such a high number of components involved in baroreflex, that only large studies on numerous probands can give reliable information. To overcome this complication, twins are often studied (Gollasch et al. 2002). Current studies have brought promising data.

Ormezzano et al. (2005) suggested that the endothelin system may be involved in the regulation of BRS in humans. In particular, the $T$ allele of the EDNRA/C $+1222 \mathrm{~T}$ polymorphism is associated with a reduction in BRS in both healthy and hypertensive subjects. It is supposed that aldosterone may have direct effects on the cardiovascular system in addition to regulation of renal sodium resorption. A polymorphism $(-344 \mathrm{C} / \mathrm{T})$ in the promoter of the aldosterone synthase (CYP11B2) gene, the presence of $-344 \mathrm{C}$ allele, is strongly associated with decreased baroreflex sensitivity in healthy individuals (White at al. 1999, Ylitalo et al. 2000). Gollasch et al. (2002) reported that genetic variation in the gene encoding the $\beta 1$ subunit of calciumactivated potassium channels (KCNMB1) is associated with altered baroreflex function and heart rate variability. It was observed that a decrease in the transcription of the bradykinin $\mathrm{B}_{2}$ receptor gene in the presence of the $\mathrm{B} 2 \mathrm{R}$ $-58 \mathrm{C}$ allele could reduce BRS via the diminished effect of bradykinin (Milan et al. 2005). We have found a linkage of baroreflex sensitivity with A1166C polymorphism in the $\mathrm{AT}_{1}$ receptor gene (Jíra et al. 2007).

\section{Low baroreflex sensitivity as an independent risk factor for essential hypertension}

It has been known that obesity is associated with a higher risk of high blood pressure in both adults and children (Rahmouni et al. 2005, Lurba et al. 1998). We compared 34 hypertonic adolescents (average age 16.6 years) with 52 healthy controls of corresponding age (Krontorádová et al. 2008). Hypertonic subjects had significantly lower BRS and a significantly higher body mass index (BMI). No correlation was found between BMI and BRS either in the group of hypertonics or in controls. The predicting power of BMI, BRS, and a combination of both factors for hypertension was evaluated by sensitivity and specificity. Optimal critical values were determined by the receiver operating curve (ROC), i.e. a plot of sensitivity versus specificity for moving critical values in steps. When we used optimal critical values of $22.2 \mathrm{~kg} / \mathrm{m}^{2}$ for BMI and $7 \mathrm{~ms} / \mathrm{mmHg}$ for BRS for the prediction of hypertension diagnosed by 24-hour blood pressure monitoring and calculation of sensitivity and specificity of each factor, we obtained values of sensitivity of both factors over $60 \%$ and of specificity over $65 \%$. As we used the ROC curve for both factors together with logistic regression analysis, we obtained sensitivity over $70 \%$ and specificity over $80 \%$. This means that low BRS is an independent risk factor for the development of essential hypertension.

In the majority of children and young people, mean blood pressure is low for the most part of the day. A moderate increase of blood pressure is observed during exercise in some cases, but it is limited for relatively short time periods during the day. Due to getting nervous, some children have higher blood pressure in the doctor's office than during the normal daytime activity. Increased blood pressure is elicited by an increase of the sympathetic nervous activity and is blunted by baroreflex. This suppression of blood pressure increase is more pronounced in children with high baroreflex sensitivity. On the other hand, in children with low BRS the suppression is insufficient and white-coat hypertension occurs.

In obese children, the situation is different. Fatty tissue produces leptin and this substance increases the sympathetic activity for the whole day. The high BRS can compensate the influence of the sympathetic activity on blood pressure; the mean blood pressure remains normal as well as the set point of the baroreflex. In children with both obesity and low baroreflex, the increased sympathetic activity by leptin secretion and thus the increased blood pressure is not sufficiently suppressed by the baroreflex; baroreflex resetting moves the set point of the baroreflex to higher values of blood pressure, and hypertension is a consequence (Honzíková et al. 2006b). 
In older people the situation is complicated by more risk factors but there is no reason to suppose that the role of obesity and baroreflex is different.

\section{Conclusions for clinical practice and for further studies}

Our studies yield results important for clinical practice and could change the current recommendations. Non-invasive baroreflex sensitivity should be examined in children and adolescents with a high causal blood pressure repeatedly measured. Patients with BRS under $7 \mathrm{~ms} / \mathrm{mmHg}$ should be more intensively observed and motivated to change their lifestyle including a lowercalorie diet and a greater physical activity. It is also necessary to take into account the risk of hypochondria, but this is not too high. Blood pressure measurement at home by an automatic device is neither time-consuming nor technically difficult. Top sport has high prestige in young people and top sportsmen are continuously medically examined. An encouragement to physical activity results in greater physical efficiency and a better social position among young people. Naturally, in some cases it would be necessary to start pharmacotherapy, which is highly effective now and with low side effects. It should be stressed that motivation to prevent hypertension and to treat it adequately is important for both the individual and the society.

Further genetic studies may provide new insight into the relationship between the family history of hypertension and low BRS. The linkage between high blood pressure and diabetes mellitus should be studied with respect to low BRS as well as vascular consequences in adults.

\section{Conflict of Interest}

There is no conflict of interest.

\section{Acknowledgements}

Supported by grant MSM 0021622402 from the Ministry of Education, Youth and Sport of the Czech Republic.

\section{References}

BROOKS VL, SVED AF: Pressure to change? Re-evaluating the role of baroreceptors in the long-term control of arterial pressure. Am J Physiol 288: R815-R818, 2005.

COWLEY AW Jr: Long-term control of arterial blood pressure. Physiol Rev 72: 231-300, 1992.

FREEDMAN DS, DIETZ WH, SRINIVASAN SR, BERENSON GS: The relation of overweight to cardiovascular risk factors among children and adolescents: The Bogalusa Heart Study. Pediatrics 103: 1175-1182, 1999.

FILIPPONE JD, BISOGNANO JD: Baroreflex stimulation in the treatment of hypertension. Curr Opin Nephrol Hypertens 16: 403-408, 2007.

GOLLASCH M, TANK J, LUFT FC, JORDAN J, MAASS P, KRASKO C, SHARMA AM, BUSJAHN A, BAHRING $\mathrm{S}$ : The BK channel $\beta 1$ subunit is associated with human baroreflex and blood pressure regulation. J Hypertens 20: 927-933, 2002.

GRIBBIN B, PICKERING TG, SLEIGHT P, PETO R: Effect of age and high blood pressure on baroreflex sensitivity in man. Circ Res 24: 424-431, 1971.

Health and consumer protection directorate - general. Fact sheet. In: European Communities, European Commission $8-1049$, Brussels, 2006.

HONZÍKOVÁ N, FIŠER B, HONZÍK J: Noninvasive determination of baroreflex sensitivity in man by means of spectral analysis. Physiol Res 41: 31-37, 1992.

HONZÍKOVÁ N, RYBKOVÁ I, HONZÍK JM: Baroreflex sensitivity, heart rate and blood pressure during mental load and emotional activation. Homeostasis 37: 72-76, 1996.

HONZÍKOVÁ N, SEMRÁD B, FIŠER B, LÁBROVÁ R: Baroreflex sensitivity determined by spectral method and heart rate variability, and two-years mortality in patients after myocardial infarction. Physiol Res 49: 643-650, 2000.

HONZÍKOVÁ N, LABROVÁ R, FIŠER B, MADĚROVÁ E, NOVÁKOVÁ Z, ZÁVODNÁ E, SEMRÁD B: Influence of age, body mass index, and blood pressure on the carotid intima-media thickness in normotensive and hypertensive patients. Biomed Tech 51: 159-162, $2006 \mathrm{a}$. 
HONZÍKOVÁ N, NOVÁKOVÁ Z, ZÁVODNÁ E, PADĚROVÁ J, LOKAJ P, FIŠER B, BALCÁRKOVÁ P, HRSTKOVÁ H: Baroreflex sensitivity in children, adolescents, and young adults with essential and white-coat hypertension. Klin Paed 218: 237-242, 2006 b.

IWASE N, TAKATA S, OKUWA H, OGAWA J, IKEDA T, HATTORI N. Abnormal baroreflex control of heart rate in normotensive young subjects with a family history of essential hypertension. $J$ Hypertens 2 (Suppl 2): S409S411, 1984.

JÍRA M, ZÁVODNÁ E, HONZÍKOVÁ N, NOVÁKOVÁ Z, FIŠER B: Baroreflex sensitivity as an individual characteristic feature. Physiol Res, 53: 349-351, 2006.

JÍRA M, ZÁVODNÁ E, HONZÍKOVÁ N, NOVÁKOVÁ Z, VAŠKŮ A, IZAKOVIČOVÁ HOLLÁ L, FIŠER B: Baroreflex sensitivity and A1166C polymorphism in $\mathrm{AT}_{1}$ receptor gene. Physiol Res 56: 15P, 2007.

KAPLAN HM: Hypertensive and atherosclerotic cardiovascular disease. In: Heart disease: a textbook of cardiovascular medicine. E. BRAUNWALD, D.P. ZIPES, P. LIBBY (eds), Saunders Company, Philadelphia, 2001, pp 941-948.

KARDOS A, WATTERICH G, DE MENEZES R, CSANADY M, CASADEI B, RUDAS L: Determinants of spontaneous baroreflex sensitivity in a healthy working population. Hypertension 37: 911-916, 2001.

KRONTORÁDOVÁ K, HONZÍKOVÁ N, FIŠER B, NOVÁKOVÁ Z, ZÁVODNÁ E, HRSTKOVÁ H, HONZÍK P: Overweight and decreased baroreflex sensitivity as independent risk factors for hypertension in children, adolescents, and young adults. Physiol Res 57: 385-391, 2008.

LURBA E, ALVAREZ V, LIAO Y, TACONS J, COOPER R, CREMADES B, TORRO I, REDON J: The impact of obesity and body fat distribution on ambulatory blood pressure in children and adolescents. Am J Hypertens 11: 418-424, 1998.

MILAN A, MULATERO P, WILLIAMS TA, CARRA R, SCHIAVONE D, MARTUZZI R, RABBIA F, VEGLIO F: Bradykinin $\mathrm{B}_{2}$ receptor gene $(-58 \mathrm{~T} / \mathrm{C})$ polymorphism influences baroreflex sensitivity in never-treated hypertensive patients. J Hypertens 23: 63-69, 2005.

NOVÁKOVÁ Z, HONZÍKOVÁ N, HRSTKOVÁ H, FIŠER B, VÁCLAVKOVÁ P: Measurement of baroreflex sensitivity in children with hypertension. Physiol Res 49: P14, 2000.

NISHIDA Y, QING HCH, MING-SHENG Z, JOUJI H: Sinoaortic denervation abolishes pressure resetting for daily physical activity in rabbits. Am J Physiol 282: R649-R657, 2002.

ORMEZZANO O, POIRIER O, MALLION JM, NICAUD V, AMAR J, CHAMONTIN B, MOUNIER-VÉHIER C, FRANÇOIS P, CAMBIEN F, BAGUET JP: A polymorphism in the endothelin-A receptor gene is linked to baroreflex sensitivity. J Hypertens 23: 1967-1969, 2005.

RAHMOUNI K, CORRELA MLG, HAYNES WG, MARK AL: Obesity-associated hypertension - new insight into mechanisms. Hypertension 45: 9-14, 2005.

SAVIN E, SIEGELOVA J, FISER B, BONNIN P: Intra- and extracranial artery blood velocity during a sudden blood pressure decrease in humans. Eur J Appl Physiol 76: 289-293, 1997.

SEMRÁD B, FIŠER B, HONZÍKOVÁ N: Ageing and cardiac autonomic status. In: Clinical Guide to Cardiac Autonomic Tests. M MALIK (ed), Kluwer Academic Publishers, Dordrecht, 1998, pp 285-300.

SOROF JM, POFFENBARGER T, FRANCO K, BERNARD L, PORTMON RJ: Isolated systolic hypertension, obesity, and hyperkinetic hemodynamic states in children. J Pediatr 140: 660-666, 2002.

STRANDGAARD S, HAUNSO S: Why does antihypertensive treatment prevent stroke but not myocardial infarction? Lancet 2: 658-661, 1987.

TANK J, JORDAN J, DIETRICH A, STOFFELS M, FRANKE G, FAULHABER HD, LUFT FC, BUSJAHN A: Genetic influences on baroreflex function in normal twins. Hypertension 37: 907-910, 2001.

THRASHER TN: Baroreceptors, baroreceptor unloading, and the long-term control of blood pressure. Am J Physiol 288: R819-R827, 2005.

WHITE PC, HAUTANEN A, KUPARI M: Aldosterone synthase (CYP11B2) polymorphism and cardiovascular function. J Steroid Biochem Mol Biol 69: 409-412, 1999.

YLITALO A, AIRAKSINEN KE, HAUTANEN A, KUPARI M, CARSON M, VIROLAINEN J, SAVOLAINEN M, KAUMA H, KESANIEMI ZA, WHITE PC, HUIKURI HV: Baroreflex sensitivity and variants of the renin angiotensin system genes. J Am Coll Cardiol 35: 194-200, 2000. 
ZAVODNÁ E, HONZÍKOVÁ N, HRSTKOVÁ H, NOVÁKOVÁ Z, MOUDR J, JÍRA M, FIŠER B: Can we detect the development of baroreflex sensitivity in humans between 11 and 20 years of age? Can J Physiol Pharmacol 84: 1275-1283, 2006. 